\title{
REFLEXÕES INICIAIS ACERCA DO DEBATE SOBRE O CAMPO DA GEOGRAFIA POLÍTICA CONTEMPORÂNEA NO BRASIL
}

\section{Reflexiones iniciales sobre el debate sobre el campo de la geografía de política contemporánea en brasil}

\author{
Vanessa Teixeira \\ Mestranda em Geografia pela Universidade Estadual do Centro- Oeste (UNICENTRO) \\ vanessateixeira1904@hotmail.com
}

Artigo recebido em 25/09/2014 e aceito para publicação em 04/12/2014

http://dx.doi.org/10.12957/tamoios.2014.13008

Resumo Esta nota de pesquisa trata das observações realizadas na construção do projeto de mestrado, vinculada ao Programa de Pós-Graduação em Geografia, pela Universidade Estadual do Centro-Oeste do Paraná. A presente proposta tem por objetivo analisar a Geografia Política contemporânea no Brasil a partir da disseminação de pesquisas nesse campo, tendo como fonte os trabalhos apresentados no Encontro da Associação Nacional de Pesquisa e Pós-Graduação (ANPEGE) pelo seu uso conceitual, observando quais foram as mudanças no período entre 1995 a 2014, trazendo por fundamentação à análise da interação da política com o território via relações de poder. A escolha do evento da ANPEGE se justifica por se tratarem de encontros de natureza nacional e especializados, além de ser uma grande representatividade aos estudos geográficos em nível de pós-graduação, pois reúne a participação de pesquisadores de todo o país. Ainda nessa perspectiva, a escolha temporal do estudo é uma tentativa de visualizar a discussão teórica, enquanto elemento do desenvolvimento do conhecimento geográfico brasileiro a partir do primeiro encontro da ANPEGE.

Palavras-chave: Geografia Política; poder; agenda temática;

Resumen Esta nota de investigación, se ocupa de las observaciones realizadas en la construcción del projecto del maestria, vinculado al Programa de Post-Grado en Geofrafía de la Universidad Estatal de Centro -Oeste. Esta propuesta tiene como objetivo analizar la geografía política contemporánea en Brasil a partir de la difusión de la investigación en este campo, en los documentos originales presentados en la Reunión de la Asociación Nacional de Investigación y Estudios de Posgrado (AMPEGE) para su uso conceptual, señalando que eran cambios en el periodo comprendido entre 1995 a 2014, con lo que el análisis por razones de interacción política con el territorio a través de las relaciones de poder. La elección del evento ANPEGE se justifica debido a que son de naturaleza encuentros nacionales y especializados, además de ser una gran representación de los estudios geográficos a nivel de post-grado, ya que incluye la participación de investigadores de todo el país. También es este punto de vista, la elección temporal de estudio es un intento de visualizar la discusión teórica, como parte del desarrolo de los conocimientos geográficos de Brasil de la primera reunión de ANPEGE.

Palabras clave: Geografía Política; el poder; agenda temática 


\section{INTRODUÇÃO}

Esta nota de pesquisa trata das observações realizadas na construção do projeto de mestrado, vinculada ao Programa de Pós-Graduação em Geografia, pela Universidade Estadual do Centro-Oeste do Paraná. A presente proposta tem por objetivo analisar a Geografia Política contemporânea no Brasil a partir da disseminação de pesquisas nesse campo, a partir da análise dos trabalhos apresentados no Encontro da Associação Nacional de Pesquisa e Pós-Graduação (ANPEGE) pelo seu uso conceitual, observando quais foram às mudanças no período entre 1995 a 2014, trazendo por fundamentação à análise da interação da política com o território via relações de poder.

Os apontamentos feitos neste trabalho, em andamento, abrem possibilidades para refletir no seu conjunto temático contemporâneo, uma vez que, a presença em seus estudos é pertinente, vem ganhando expressão e não se encontra limitado, ao contrário, reúne um vasto campo de investigação sobre a dimensão espacial da política (CASTRO, 2005).

Em relação à dimensão espacial, o mesmo envolve diferentes relações que nele ocorre: relações políticas, econômicas, sociais e culturais. Na dimensão política, esses espaços podem ser identificados como, fronteiras, unidades políticas, centros, entre outros, com significativos interesses, poder e dominação. Segundo Castro (2005), o espaço geográfico é intrinsecamente político, é uma arena de conflitos e, consequentemente, de normas para regulação que permite seu controle, e, dentro dessa visão, quando muda a escala mudam-se os atores e interesses, que se traduzem, entre outros aspectos, na camuflagem de estratégias de grupos de poder. Dessa forma, os fenômenos políticos emergem a partir de problemas que não são inatos, mas construídos, e que, na maioria das vezes, são apresentados como elementos naturais da sociedade. Assim, refletir sobre os debates teóricos contemporâneos em Geografia Política, nos leva pensar acerca do que se tem produzido em estudos científicos nos últimos anos na comunidade geográfica, suas indagações, tendências, preferências, possibilidades e os desafios abertos a esse campo.

Sob tal conjuntura, ao contrário de sua agenda temática, quando se instituiu no século XIX, que o Estado era uma unidade primária de análise (GALLAHER, 2009), isto é, "tinha no Estado nacional o eixo teórico conceitual em torno do qual sua agenda da disciplina era definida, porque afinal, em torno dele que o próprio mundo se organizava" os estudos em Geografia Política procuram na contemporaneidade, responder aos desafios dos fenômenos em escalas múltiplas (CASTRO, 2005) e não unicamente estudos do Estado enquanto único poder político.

Nesse sentido, trata-se de uma Geografia Política com uma agenda de estudos acompanhada pelas transformações que se configuram globalmente, nacionalmente e localmente, incorporando discussões conceituais das ações que se instituem no espaço (CASTRO, 2013) e não unicamente nos estudos do Estado-Nação. Junto a isso, acrescentaram-se outras unidades de análise para o seu repertório, incluindo os níveis, não só de análise menores, como o local, mas também os maiores, como o supranacional com uma renovada atenção às diferentes maneiras que as ações políticas atuam (GALLAHER, 2009).

Por outro lado, ao discutir as temáticas em Geografia Política não é simplesmente resumir suas delimitações geográficas em suas diferentes escalas analíticas e temporais, mas também, conhecer suas complexidades, ângulos e problemáticas dentro da análise de natureza política.

Todos esses elementos vinculam-se a questão central da nossa pesquisa, que parte da seguinte inquietação: sob qual profundidade em estudos tem a Geografia Política emergindo na comunidade geográfica brasileira nos últimos anos? Quais os seus avanços, retomadas, "tendência" em estudos elou "(re) leituras" contemporâneas? E diante das problemáticas presentes hoje na sociedade, quais as temáticas priorizadas nas discussões dos geógrafos? 


\section{OS CAMINHOS DA PESQUISA: CONSTRUÇÃO METOLÓGICA}

As técnicas e materiais de pesquisa são fundamentais e norteadores nas pesquisas científicas, elas constituem as bases para a análise da problemática pretendida. Dessa forma, essas são cada vez mais centrais ao entendimento, aproximação e distinções do objeto de estudo, sendo indissociável em qualquer análise na compreensão da realidade.

Percebe-se que a Ciência Geográfica é privilegiada em um conjunto de técnicas de pesquisa, as quais permitem uma flexibilidade teórica e epistemológica para tratar cientificamente em seus estudos. Nas escolhas dos geógrafos se pressupõem a melhor técnica operacional metodológica adequada a sua pesquisa para se atingir um destino, selecionadas de acordo com a natureza do assunto estudado para uma interpretação dos fenômenos, constituindo, assim, uma dinâmica entre pesquisador e sujeitos da pesquisa.

Conforme Silva \& Mendes (2013, p.208) "a pesquisa tem por finalidade conhecer as contribuições científicas efetuadas sobre determinada temática", na qual, devido às particularidades de cada subárea da Geografia, adotam-se diferentes métodos e técnicas de análise, que abrem possibilidades de discutir os mecanismos presentes em determinadas relações, eventos, processos, e fenômenos que influenciam no espaço.

No âmbito da aplicação instrumental técnico e metodológico será adotado neste estudo a análise de conteúdo e a pesquisa teórica, enquanto proposta analítica, analisando as comunicações dos Anais dos Encontros da Associação Nacional de Pesquisa e Pós-Graduação em Geografia (ANPEGE), verificando os conteúdos dos trabalhos publicados, isto é, o reconhecimento dos conceitos mais utilizados pelo autor do texto e suas concepções do fenômeno estudado.

É importante ressaltar a dificuldade que se encontra ao trabalhar com análises de Anais dentro das pesquisas, uma vez que, a análise não é simples, e tem-se, por exemplo, a falta de acesso aos mesmos e/ou ausência quando trabalha com uma longa periodicidade de um evento científico.

Corrobora-se, portanto, com Silva; Silva (2013, p.421), quando afirma que "não devemos julgar as obras [e os Anais] pelo que elas não têm, mas sim, buscar nelas, o que pode haver de importante para a pesquisa". Sob tal perspectiva, procura-se valorizar a palavra escrita, esta que "ocupa lugar de destaque nessa abordagem [pesquisa qualitativa] e desempenha um papel fundamental tanto no processo de obtenção de dados quanto na disseminação dos resultados" (SOTRATTI; MARAFON, 2013, p.196), e oferece possibilidades para responder, em relação aos trabalhos realizados, a respeito da Geografia Política em cada evento.

Por conseguinte, a pesquisa teórica e análise do conteúdo assumem papeis fundamentais e complementam-se neste estudo. Esta primeira confirma especificamente, os avanços, "tendências" em estudos, possibilidades de leitura dessa nova realidade ou conjunturas do cenário dos fenômenos políticos. Diante disso, adotamos o ponto de vista estabelecido por Silva \& Mendes (2013, p.208) que a "pesquisa teórica não deve ser considerada mera repetição do que foi dito ou escrito, mas sim, um campo que propicia o exame de um tema sob novo enfoque ou abordagem, o que possibilita análises inovadoras".

De fato, a "pesquisa teórica possibilita estabelecer uma relação com o objeto de pesquisa, dá suporte ás hipóteses e constroem o principal para a interpretação de seus resultados" (SILVA \& MENDES, 2013, p.209), e ainda, podem ser complementadas pelo uso de várias técnicas de pesquisas, neste caso, com o uso da análise de conteúdo. Sendo assim, "ela tem por finalidade conhecer as contradições científicas que se efetuaram sobre determinando assunto, bem como as principais lacunas existentes" (SILVA \& MENDES, 2013, p.209) na realidade a ser pesquisada.

A análise de conteúdo é uma técnica que existe a mais de meio século no âmbito das ciências humanas, e em seu uso, atualmente, ela envolve três fases específicas, sendo elas: a) préanálise; b) análise do material; c) tratamento dos resultados (SANTOS; RAMIRES, 2009, p.163). Ao usar essas técnicas, elas podem ser aplicadas em diferentes materiais, como: Jornais; entrevistas, artigos de periódicos; Dissertações; Anais de eventos, entre outros, para isso, concordamos com o ponto de vista estabelecido por Gobbi \& Pessôa (2009, p.487) quando afirmam que a "análise de conteúdo, reduz o risco de enquadramento, forçosamente, a realidade em modelos, uma vez que, pelo procedimento que adota, permite que questões não suscitadas possam emergir no avanço da pesquisa".

Ainda em relação à análise de conteúdo, há vários procedimentos que envolvem a pesquisa e uma delas é a codificação, que abrange três etapas: a determinação das unidades de registro e 
contexto; regras de numeração; categorização (SANTOS; RAMIRES, 2009, p.164), por isso, consideramos pertinente uma análise embasada na escrita das pesquisas [trabalhos publicados nos anais do evento], pois isso permite uma possível representação no que integra essa "trajetória" em estudos recentes.

A esta pesquisa, ao utilizar a análise do conteúdo dos Anais como fontes de dados e informações, implicam-se ter em mente também alguns aspectos, tais como o tempo histórico dos pesquisadores, contexto espacial/temporal de cada encontro realizado, suas entidades promotoras, a temática e proposta em cada edição dos eventos, e, assim, para não "comprometer" a validade do estudo.

Neste sentido, é propicio uma aproximação a seu respeito desse evento.

\section{ANPEGE E A PESQUISA GEOGRÁFICA NO BRASIL}

O Encontro da Associação Nacional da Pós-Graduação em Geografia (ANPEGE) é de natureza nacional que reúne discentes e docentes de pós-graduação de todo Brasil, marcado por uma significativa representatividade aos estudos geográficos e com periodização a cada dois anos, além de promover um diálogo entre os programas de pós-graduação.

Avançando na discussão, a criação da ANPEGE se estabelece por volta de 1993, embora anos antes já se tinha uma realização de encontros preliminares da pós-graduação (SILVA, 2009). Ainda segundo Silva (2009, p.85) naquele período "as bases da pós-graduação brasileira já estavam postas e consolidadas, como também o sistema de avaliação delineado", do mesmo modo, a CAPES fazia referência enquanto órgão regulador da Pós-graduação e impõe a uma importante agência de fomento do ensino e da pesquisa. De algum modo, a criação da ANPEGE marca uma afirmação da Pósgraduação em Geografia, pois, até então, encontrava-se ainda muito dispersa no Brasil aos interesses teóricos e a demanda de fazer pesquisa.

Em relação ao seu espaço de encontro, o evento da ANPEGE compreende conferências, mesas Redondas de debate, homenagens, sessões de comunicações livres; espaços para grupos de trabalho; fóruns de coordenadores; sessão de pôsteres; lançamento de livros e revistas, etc. Logo, após o final do encontro, é eleita a uma nova diretoria, composta por professores de distintos Programas, se responsabilizando para a organização do próximo evento. Complementarmente, é pertinente que, nesta pesquisa, se resgate, que sua primeira diretoria foi constituída pelo Prof. Dr. Milton de Almeida Santos - USP (Presidente); Profa. Dra. Maria Adélia Aparecida de Souza - USP (Secretária) e Profa. Dra. Amalia Inés Geraiges de Lemos - USP (Tesoureira). Constituindo assim, naquele momento um trio de pesquisadores de renome em estudos geográficos.

No quadro a seguir, sistematizamos em um levantamento do ano e local da realização dos eventos, juntamente com suas respectivas temáticas até o momento, neste sentido, elaboramos uma cronologia dos encontros da ANPEGE.

Quadro 1 - Cronologia dos encontros da ANPEGE

\begin{tabular}{|c|c|c|c|}
\hline ANPEGE & Ano ${ }^{1}$ & Temáticas dos eventos & Cidade / Estado \\
\hline I & 1995 & Território Brasileiro e Globalização & Aracaju - SE \\
\hline II & 1997 & Desafios e Alternativas para a Gestão do Território & Rio de Janeiro- RJ \\
\hline IV & 2001 & A Geografia no Século XXI & São Paulo - SP \\
\hline $\mathrm{V}$ & 2003 & $\begin{array}{l}\text { Gestão do território no Brasil: Desafios à formação e a } \\
\text { pesquisa em geografia no ensino superior }\end{array}$ & Florianópolis - SC \\
\hline VII & 2007 & $\begin{array}{c}\text { Espacialidade Contemporânea: o Brasil, a America } \\
\text { Latina e o Mundo }\end{array}$ & Rio de Janeiro - RJ \\
\hline VIII & 2009 & $\begin{array}{c}\text { Espaço e Tempo: complexidades e desafios do pensar e } \\
\text { do fazer geográfico }\end{array}$ & Curitiba - PR \\
\hline IX & 2011 & $\begin{array}{l}\text { A pesquisa e a produção geográficas: o pulsar no tempo e } \\
\text { no espaço }\end{array}$ & Goiânia - GO \\
\hline $\mathrm{X}$ & 2013 & Geografias, políticas públicas e dinâmicas territoriais & Campinas - SP \\
\hline
\end{tabular}

Org.: TEIXEIRA, V. (2014)

Fonte: Anais da ANPEGE. 
Todo evento é guiado por uma temática principal, inserindo-se enquanto um grande eixo de reflexão. Os eventos da ANPEGE mostraram uma preocupação com a pesquisa e o ensino de Geografia e as grandes questões que se colocam para o geógrafo em relação à "transformações" sob a perspectiva espacial e temporal, como podemos observar no quadro 1. Além disso, há em seus eventos científicos questões importantes nas mudanças que estão em curso: informações, resultados, possibilidades e inserções de novos conhecimentos teóricos com enfoque geográfico que venham a somar na produção científica.

\title{
BREVES CONSIDERAÇÕES
}

Ao trazer a agenda temática da Geografia Política em pauta para discussão, a presente pesquisa contribui para afirmação de que este não é um assunto "resolvido", acreditamos assim, que os "temas se impõem a reflexão nas diferentes áreas do conhecimento como efeito de evidências da realidade" (CASTRO et al, 2013, p.11), para a Geografia Política isso não é diferente, pois, em relação as últimas décadas

\begin{abstract}
a geografia é desafiada a repensar o território, sobretudo, quando é gestado um novo mapa do mundo: novas fronteiras são criadas, algumas redesenhadas, outras desaparecem, enquanto a regra geral é serem atravessada por fluxos de mercadorias (legais e ilegais) e informações sem precedentes; territórios são fragmentados, outros são unificados; novas hegemonias são construídas, assim como antigas alianças são esfaceladas; uma nova geopolítica surge para confrontar blocos de poder; novas formas de fazer guerra confrontam o tradicional Estado-territorial; novos blocos geoeconômicos unem territórios em benefícios do mercado mundial [...] (CATAIA, 2011, p.116).
\end{abstract}

Verificamos assim, uma complexidade dos elementos na dimensão política na contemporaneidade para os estudos geográficos.

Em relação à disseminação de seus estudos, apesar de constituir uma das subáreas mais antiga e bem estabelecida da ciência geográfica, algumas de suas temáticas ainda não se colocam explicitamente em discussões. No Brasil, a produção em estudos da Geografia Política é muito recente e são exíguos as obras desenvolvidas, as disseminações de suas pesquisas remontam, principalmente, as últimas décadas, ressaltando algumas temáticas, que até então, estavam ausentes dos debates dos Geógrafos. Além da continuidade das abordagens clássicas, somam-se novas preocupações e elementos, discutindo sobre as políticas públicas, paisagem política, questões eleitorais e democráticas do país e seus recortes institucionais, territórios políticos marcado pelo poder religioso, entre outras. Do mesmo modo, a descoberta da escala local vem ampliando sua pauta das investigações. Entretanto, constata-se uma necessidade em estudos em direção ao sistema político, às escalas de governos, que revelam conflitos de interesse e afetam o território.

Estes apontamentos buscam contribuir com as reflexões sobre sua agenda de pesquisa nos últimos anos, as lacunas e temáticas pouco exploradas, permitindo, assim, uma maior visibilidade ao seu corpo teórico. Verifica-se, ainda, que há uma "impossibilidade de compor uma agenda completamente abrangente, tem se conduzindo a uma seleção e ordenamento de certos temas e questões somando-se as tradicionais." (CASTRO, 2005, p.18). Desse modo, um dos grandes desafios dentro da Geografia Política hoje é incorporar os fatos e as dinâmicas que trazem o novo e, simultaneamente, considerar e interpretar o antigo diante de um cenário complexo de relações e interesses (CASTRO, 2005), por exemplo: as redes de comunicação e informação exercem um papel significativo na sociedade, colaboram para modelar o espaço - tempo, são meios de estruturação do poder no espaço geográfico, atuando para "supervisionar" populações, governos, recursos, economias etc. (RAFFESTIN, 1993).

O tratamento da temática sobre o Estado, por exemplo, sua presença ainda que se mostre mais diluída na relação campo-cidade, está visível enquanto um elemento no controle do espaço. Esse fato evidencia a questão estatal do território, a qual deixou de ser um elemento geral (contexto histórico da Europa Ocidental do século XIX) e reside como conflitos localizados. 
Deste modo, podemos verificar no contexto mundial atual, novas problemáticas específicas e pluralistas diante das fortes relações de políticas de empresas e corporações. De acordo com Limonad (2014), a inserção de projetos nacionais no Brasil se sustentou em estratégias territoriais que possibilitou a ocupação do espaço e deu lugar a distintas regionalizações, assim, na "última década, entre 2004 e 2014, as grandes corporações em parceria com o Estado articulam-se internacionalmente e passam a interferir de forma mais incisiva e direta nas formas de uso e apropriação do território" (LIMONNAD, 2014, p.12).

Acerca da temática do poder, os geógrafos políticos analisam sua manifestação espacial e, em particular, se questionam sobre a localização, distribuição das relações de poder, mas cada vez mais, analisam a forma como o poder é incorporado individualmente e por grupos distintos (GALLAHER, 2009).

A partir dessa breve aproximação, acreditamos que os textos publicados nos Anais possam conduzir sua trajetória de pesquisa percorrida no "espaço científico", neste caso, oferecendo uma significação a densidade ou não da presença em determinados estudos.

\section{NOTA}

1 - No ano de 1999 realizou-se o III encontro da ANPEGE, e no ano de 2005 se realizou o VI encontro. Porém, não obtivemos acesso aos Anais correspondente aquele momento, do mesmo modo, não foi encontrado as informações sobre o local de realização e suas temáticas gerais.

\section{REFERÊNCIAS}

BECKER, Bertha Koiffman. Geografia Política e território no pensamento geográfico brasileiro contemporâneo. Ateliê Geográfico, Goiânia-GO, n. 4. Dezembro, p.281-298, 2010.

CATAIA, Marcio Antonio. Território político: fundamentos e fundação do Estado. Revista Sociedade \& Natureza. Uberlândia, v. 23, n.1, p.115-125, 2011.

. Quem tem medo das fronteiras no período da globalização? Revista Terra Livre, São Paulo-SP, v1, n.40, p.65-80, 2013.

CASTRO, Iná Elias de. Geografia e política. Território, escalas de ação e instituições. Rio de Janeiro: Bertrand Brasil, 2005.

et al. RODRIGUES, Juliano Nunes; RIBEIRO, Rafael Winter (org). Espaços de

Democracia para a agenda da geografia política contemporânea. $1^{a}$ ed. Rio de Janeiro: Bertrand BrasillFaperj, 2013.

O espaço político: limites e possibilidades do conceito. In CASTRO, Iná Elias de; GOMES, Paulo César da Costa; CORREAA, Roberto Lobato. Olhares Geográficos: modos de ver e viver o espaço. Bertrand Brasil, Rio de Janeiro, 2012.

GALLAHER, Carolyn. Hegemony In. GALLAHER, Carolyn et AL. Key Concepts in Political Geography. Londres: Sage, 2009.

GOBRI, Wanderléia Aparecida de Oliveira; PESSÔA, Vera Lúcia Salazar. Pesquisa qualitativa em Geografia: reflexões sobre o trabalho de Campo. In Julio Cesar de Lima Ramires; Vera Lúcio Salazer Pessoa (Org). Geografia e pesquisa qualitativa nas trilhas da investigação. Uberlândia: Assis, 2009.

LIMONNAD, Ester. Estado, espaço e escala no Brasil, subsídios para a Reflexão. Scripta Nova, Barcelona. Vol. XVIII, n. 493, p. 01-19, 2014

MENDES, Estevane de Paula Potes; PESSÔA, Vera Lúcia Salazar. Técnicas de investigação e estudos agrários: entrevistas, registros de observações e aplicação de roteiro de entrevista. In Julio Cesar de Lima Ramires; Vera Lúcio Salazer Pessoa (Org). Geografia e pesquisa qualitativa nas trilhas da investigação. Uberlândia: Assis, 2009.

RAFFESTIN, Claude. Por uma geografia do poder. São Paulo: Ática, 1993. 
ROSA, Roberto. Análise espacial em geografia. Revista da ANPEGE, v. 7, n. 1, p. 275-289, out. 2011.

SANTOS, Márcia Andréia Ferreira; RAMIRES, Julio Cesar de Lima. A violência urbana em Uberlândia nas reportagens de jornal: um exemplo de análise de conteúdo. In Julio Cesar de Lima Ramires; Vera Lúcio Salazer Pessoa (Org). Geografia e pesquisa qualitativa nas trilhas da investigação. Uberlândia: Assis, 2009.

SÁNCHEZ, Joan Eugeni. Geografía política. Madrid: Editorial Sintesis, 1992.

Poder y Espacio. Universidad de Barcelona, Año IV. nº 23, Sep. 1979. Disponível em:<http://www.ub.edu/geocrit/geo23.htm>. Acesso em: 15 Jul. 2014

SILVA, Juniele Martins; MENDES, Estevane de Paula Pontes. A abordagem qualitativa e geografia: pesquisa documental, entrevista e observação. In MARAFON, Glaucio José (Org). Pesquisa qualitativa em geografia: reflexões teórico-conceituais e aplicadas. Rio de Janeiro: EdUERJ, 2013. SILVA, José Borzacchiello da; OLIVEIRA, Márcio Piñon de. A trajetória da pós-graduação no Brasil e a ANPEGE: algumas questões. Revista da ANPEGE. v. 5, 2009.

SILVA, Rene Gonçalves Serafim; SILVA, Vicente de Paulo da. Pesquisa social aplicada a geografia: histórias de vida como fonte de documentação. In MARAFON, Glaucio José (Org). Pesquisa qualitativa em geografia: reflexões teórico-conceituais e aplicadas. Rio de Janeiro: EdUERJ, 2013. 